\title{
Discurso, poder e mídia na Venezuela da era Chávez
}

\author{
Discourse, power and media in Venezuela's Chavez era \\ Discurso, poder y medios de comunicación \\ en la Venezuela de la era Chávez
}

Losandro Antônio Tedeschi ${ }^{\mathrm{a}}$
Anatólio Medeiros Arce

Resumo: Este artigo destaca o discurso e sua propagação através da mídia como a principal forma de exercício de poder na Venezuela da era Chávez (1999-2013). Estes três conceitos (discurso, poder e mídia/dispositivo) são compreendidos bom base em Michel Foucault a quem tais conceitos foram marcantes em sua trajetória intelectual. $\mathrm{O}$ artigo discute rapidamente os conceitos de poder e o discurso em Foucault para, em seguida, analisá-los como eles são materializados na realidade política venezuelana. Isso porque a era Chávez foi um momento histórico de intensa efervescência política, popularização das opções de mídia e, principalmente, o país foi comandado por um líder que priorizou a própria exposição e de suas políticas, o que acabou por transformá-lo em um presidente midiático.

Palavras-chave: Dispositivo. Hugo Chávez. Michel Foucault. Venezuela.

Abstract: This article aims to discuss about the discourse and its diffusion through the media as the main way to exercise the power during Chavez administration (1999-2013). These concepts (discourse, power and media/dispositif) are understood based on Michel Foucault's epistemological conceptions, to whom these concepts were remarkable on his intellectual trajectory. To begin with this article examines rapidly the concepts of discourse and power according to Michel Foucault. After

\footnotetext{
a Doutor em História Latino-americana, pesquisador em História das Mulheres, Gênero, Interculturalidade e Memória. Professor do Programa de Pós-Graudação em História - PPGH da Universidade Federal da Grande Dourados, UFGD, e coordenador da Cátedra UNESCO "diversidade cultural, gênero e fronteiras" e do Laboratório de Estudos de Gênero, História e Interculturalidade, LEGHI. <losandrotedeschi@ufgd.edu.br>.

${ }^{\text {b }}$ Doutorando e Mestre em História pelo Programa de Pós-graduação em História da Universidade Federal da Grande Dourados (UFGD). Bacharel em Ciências Sociais pela mesma instituição. Pesquisador em História da América Latina, governo Chávez, Cuba e Integração Latinoamericana.<anatólio.arce@r7.com>.
} 
that, it proposes to understand how these concepts can be materialized in Venezuelan political reality through media. The Chavez era was a historical period of intense political effervescence and diffusion of media options. Furthermore the country was commanded by a leader who had as a priority to promote his own exposition and his politics, what ended up becoming him a midiatic president.

Keywords: Dispositif. Hugo Chavez. Michel Foucault. Venezuela.

Resumen: El artículo se ocupa del concepto de discurso y su difusión a través de los medios de comunicación como la principal forma de ejercicio de poder en la Venezuela de Chávez (1999-2013). Estos tres conceptos (discurso, poder y medios de comunicación/dispositivos) son comprendidos bajo el punto de vista de Michel Foucault, para quien los conceptos fueran muy importantes en su trayectoria intelectual. Primeramente el artículo discute los conceptos de poder y discurso en Foucault. Después, busca analizar como ellos son materializados en la realidad política venezolana. El gobierno de Chávez fue un momento histórico de efervescencia política, popularización en las opciones de medios de comunicación y la nación fue presidida por alguien que priorizó la propia exposición y de sus políticas, lo que le otorgó el rango de presidente mediático.

Palabras clave: Dispositivo. Hugo Chávez. Michel Foucault. Venezuela.

\section{Introdução}

O domínio do discurso e o bom uso da mídia foram as principais estratégias utilizadas durante o governo do presidente Hugo Chávez na Venezuela no tocante ao exercício do poder de presidente da República. Isso fez com que esse país conhecesse uma forma particular de exercício do poder presidencial e, sobretudo, da relação de poder existente entre um líder ante seus partidários e adversários, algo relacionado não apenas ao contexto vivido naquele momento como também pela própria personalidade de Chávez. Contudo, entre 1999 e 2013, a Venezuela não foi uma realidade de fácil definição e tampouco de ser superficialmente explicada em termos históricos. O país apresentou particularidades, as quais podem ser vislumbradas pela forma como um líder político ascendeu, exerceu e se manteve no poder durante o período analisado.

Hugo Chávez foi eleito presidente da Venezuela em dezembro de 1998 e tomou posse em fevereiro de 1999. No momento, o país vivia uma profunda crise estrutural que já vinha impactando-o negativamente desde a década de 1980, pondo em colapso seu modelo econômico (rentista) e seu sistema político (bipartidarismo-oligárquico). O próprio surgimento de Chávez no cenário político foi produto dessa crise, pois em 4 de fevereiro de 1992, um grupo de militares comandados pelo na 
época tenente-coronel Chávez tentou tomar o poder por intermédio de um golpe de Estado.

Por isso, ele sempre foi visto pela mídia venezuelana e internacional como uma figura polêmica e controversa, ainda mais quando se posicionou radicalmente contra o encolhimento do Estado, a supremacia do mercado e a hegemonia norte-americana no cenário internacional, propostas que estavam em voga na década de 1990. Inicialmente rejeitado pela estratégia adotada para atingir tal propósito (a insurreição militar), sua imagem não poucas vezes esteve atrelada ao autoritarismo, a demagogia e ao populismo, crítica compartilhada por outros países latino-americanos e pelos Estados Unidos. Chávez foi considerado mais um líder populista, dentre os inúmeros que existiram na América Latina do século XX. Tendo como base a estratégia da conciliação entre os setores sociais com interesses aparentemente dissonantes, o populismo foi uma estratégia de exercício de poder recorrente na América Latina do século XX. Porém, Chávez não agiu dessa maneira. Ao invés de conciliar com a antiga oligarquia político-petroleira que governou a Venezuela durante o Pacto de Punto Fijo (1958-1998), ele a enfrentou, a colocou na defensiva no jogo político, pois a venceu eleitoralmente, e reduziu sua influência de modo significativo na sociedade venezuelana. Sendo assim, optou em focar tal relação de poder em seus discursos e em difundi-los através do eficiente uso da mídia.

Dessa forma, o objetivo desse artigo é enxergar a realidade política da Venezuela na era Chávez com base nos conceitos de poder, discurso e mídia (dispositivo), tomando-os como base na perspectiva de Michel Foucault, pois tais elementos estavam presentes na Venezuela da era Chávez de uma forma nítida, porém particular. O poder, entendido como uma relação de poder, foi exercido sob uma lógica bilateral, assim como em qualquer relação humana. Os discursos foram utilizados por Chávez como uma forma de construir as verdades. Em todo este bojo, a mídia foi o principal dispositivo pelo qual o regime propagou suas ideias. Os resultados podem ser enxergados nas várias eleições, plebiscitos, referendos e demais consultas populares que venceu em 14 anos na presidência.

Trata-se, portanto, de um exercício de difícil realização, tendo em vista que os desdobramentos políticos ocorridos na era Chávez não são fáceis de serem explicados, e podem ser enxergados através de vários aspectos, pontos de vista e referenciais teórico-metodológicos. Ademais, Foucault possui outros conceitos igualmente cruciais no entendimento do vasto referencial epistemológico que compõe seu pensamento, tais 
como sujeito, disciplina, arqueologia, genealogia, etc. Todavia, para fins dessa análise e dos modestos objetivos estabelecidos para tal, somente três desses conceitos serão problematizados: poder, discurso e dispositivo.

$\mathrm{O}$ artigo está dividido em dois itens. No primeiro, faz-se uma breve descrição dos conceitos de poder e discurso com base em Foucault. Em seguida, discute-se em termos concretos como tais elementos são aplicados por intermédio da mídia, o principal dispositivo utilizado na era Chávez, o que lhe outorgou o referencial de presidente midiático. Por fim, apresentam-se as considerações finais.

\section{Discurso e poder na perspectiva de Michel Foucault}

Discurso e poder são conceitos fundamentais na compreensão do pensamento foucaultiano, sendo base na construção do que esse pensador denominou de arqueologia do saber. A aplicação dessa arqueologia e todo significado que gira em torno dela são primordiais à compreensão de determinada realidade, a qual é construída sob a lógica de uma completa ausência de neutralidade. Com uma explicação profunda da forma como as estruturas foram erigidas em determinado momento histórico, o discurso e o poder estão intimamente ligados ao saber, com a finalidade de reproduzir ou construir estruturas de dominação/ verdades (Foucault, 2013, p. 214-236). Ou seja, a arqueologia seria um "balanço desmistificador", pois trabalha com a verdade no tempo (Veyne, 2011, p.24-25). Seguindo esse raciocínio, Foucault desfaz as verdades historicamente construídas, se atentando não somente a descrição e a compreensão dos conceitos, como também enfatizando a importância da linguagem em particular e das palavras no geral, como pontos essenciais na construção do saber/verdade, realizadas por intermédio das instituições e demais aparelhos do Estado/dispositivos.

Portanto, para esse filósofo, o poder não é algo possível de ser meramente definido, mensurado ou enxergado, ele é exercido por intermédio de relações de poder, podendo suscitar tanto uma aceitação quanto uma resistência em relação àquele que exerce qualquer forma de poder sobre outro indivíduo. Ou seja, poder corresponde a relações de poder, das quais não podemos escapar, porém sempre há a possibilidade de modificá-las, pois se trata de uma relação bilateral (Veyne, 2011, p. 168), que é diversificada, sistematizada e ordenada em seu mais alto grau de eficácia. Seguindo tal lógica, o poder é exercido em toda e qualquer tipo de relação humana e vem acompanhado pelas diferentes 
formas de resistência, igualmente basilares na análise foucaultiana, contra diferentes formas de poder.

Por isso, uma das inovações propostas por Foucault foi pensar o poder descolado da lógica de que ele é exercido exclusivamente pelo Estado, colocando-o como algo pulverizado na sociedade e inerente às práticas cotidianas nas relações humanas, definindo: "[poder] é aquele que exercemos sobre as coisas e que dá a capacidade de modificálas, utilizá-las, consumi-las ou destruí-las - um poder que remete a aptidões diretamente inscritas no corpo ou mediatizadas por dispositivos instrumentais" (Foucault, 1995, p. 240). Em linhas gerais, não há como pensar qualquer análise ou algum conceito de Foucault sem reportar à lógica que orienta o poder, ou as relações de poder estabelecidas por intermédio de uma complexa estrutura norteadora.

Com perspectiva semelhante, o discurso é entendido como uma prática coletiva, historicamente construída através de palavras, visando sistematizar o domínio do saber. "O texto primeiro se apaga e, com ele, todo o fundo inesgotável de palavras cujo ser mudo estava inscrito nas coisas; só permanece a representação, desenrolando-se nos signos verbais que a manifestam e tornando-se assim discurso" (Foucault, 2007, p. 109). Para Foucault, os discursos definem as ciências do homem, pois seu nascimento ou o surgimento de suas formas discursivas está ligado ao domínio de uma ciência, ideologia, ou teoria. Por isso, "os discursos são as lentes através das quais, a cada época, os homens perceberam todas as coisas, pensaram e agiram; elas se impõem tanto aos dominantes quanto aos dominados [...]" (Veyne, 2011, p. 50-51). Dessa forma, o discurso ocupa um espaço central no pensamento foucaultiano, descrevendo como se desenrolam as relações de poder nas sociedades, permitindo analisar por inúmeros aspectos como algo é construído e/ou absorvido por setores sociais a fim de obter, manter ou aumentar suas posições em determinada sociedade.

Portanto, "[...] o discurso não é simplesmente aquilo que traduz as lutas ou os sistemas de dominação, mas aquilo [...] pelo que se luta, o poder do qual nos queremos apoderar" (Foucault, 2012, p. 10). Em termos práticos, a ciência é entendida como um discurso coletivo historicamente construído, ou seja, não é nada mais do que discursos (Foucault, 2013, p.38-48). Dessa característica, compreende-se o conceito de disciplina destacado por Foucault como o princípio do controle da produção desse discurso. "Ela [disciplina] lhe fixa os limites pelo jogo de uma identidade que tem a forma de uma reatualização permanente das regras" (Foucault, 2012, p. 34). 
O discurso, portanto, é uma forma de exercício do poder, seja ele coletivo ou individual. No que diz respeito as fundamentações teórico-metodológicas, o entendimento é de que os discursos, no sentido foucaultiano, se inserem no campo das representações sociais, conforme conceito desenvolvido por Chartier (1990). Para este autor, as representações estão conectadas aos interesses dos grupos sociais, e neste sentido, é possível dizer que ao difundir o processo político conhecido como Revolução Bolivariana, os discursos do presidente Chávez aludem a representações construídas em sintonia com seus projetos políticos e interesses, visando se consolidar e se manter no poder. Neste sentido, as representações se entrelaçam às lutas políticas que ocorrem através dos discursos e no campo das representações.

Com base nos conceitos analisados acima, chega-se ao ponto fulcral dessa análise: a compreensão dos discursos do presidente Chávez na Venezuela como uma forma de exercício do poder e de construção de verdades, as quais foram concretizadas no processo político denominado de Revolução Bolivariana. Nesse sentido, o papel desempenhado pelos meios de comunicação (sejam eles favoráveis ou contrários ao regime) influenciou significativamente nos acontecimentos políticos na Venezuela da era Chávez, tal como é discutido no próximo item.

\section{Hugo Chávez: um presidente midiático}

Uma construção eficiente do discurso presidencial por intermédio da mídia foi uma das principais formas de exercício do poder realizada por Hugo Chávez na Venezuela entre 1999 e 2013. Tal especificidade foi uma das principais características de sua gestão, colocando-o no patamar de um líder carismático ${ }^{1}$ e midiático. Esses dois atributos são essenciais a qualquer figura política a fim de construir dispositivos capazes de não somente sustentar o apoio popular a suas políticas, como também lhe reconduzir eleitoralmente ao cargo. Durante a era Chávez, a mídia foi o principal dispositivo pelo qual o regime difundiu suas políticas, ações e pensamento. Visava-se manter Chávez na presidência da República, através de sua perspicaz inserção nas massas com o exercício do monopólio das verdades colocadas no espaço público. $\mathrm{Na}$ perspectiva de Foucault (2013b) dispositivo seria:

\footnotetext{
${ }^{1}$ Para Weber, o carisma é um tipo de dominação construído em virtude da devoção à pessoa em
} razão de heroísmo, poder intelectual e de oratória (Weber, 1986, p. 134-135). 
[...] um conjunto decididamente heterogêneo que engloba discursos, instituições, organizações arquitetônicas, decisões regulamentares, leis, medidas administrativas, enunciados científicos, proposições filosóficas, morais, filantrópicas. [...] O dispositivo, portanto, está sempre inscrito em um jogo de poder, estando sempre, no entanto, ligado a uma ou a configurações de saber que dele nascem mas que igualmente o condicionam (Foucault, 2013b, p. 364-367).

Todavia, o conceito de dispositivo não deve ser simplificado e tampouco a mídia venezuelana entendida como a totalidade dos dispositivos utilizados por Chávez para se manter no poder. Para além de uma perspectiva simplista, esse conceito foucaultiano deve ser entendido como "[...] menos o determinismo que nos produz do que o obstáculo contra o qual reagem ou não reagem nosso pensamento e nossa liberdade. Estes se ativam contra ele na medida em que o próprio dispositivo é ativo" (Veyne, 2011, p. 169). Portanto, a mídia está englobada em todo esse bojo, sendo mais um dispositivo e não o único. Porém, foi o principal deles dentre os inúmeros utilizados a fim de manter Chávez como presidente da Venezuela, junto aos demais aparelhos inerentes ao Estado (poderes da República, Exército, polícia, burocracia, impostos, etc.). Além disso, no início do século XXI, o uso desse dispositivo, isto é, da mídia, se tornou ainda mais primordial e abrangente àqueles líderes políticos de forte inserção nas massas, focalizados na liderança pessoal e portador de um discurso calcado como a única verdade existente. Segundo Nogueira e Ribeiro (2013),

A construção de percepções e pressupostos coletivos relacionase à capacidade de difusão de códigos a serem compartilhados por uma coletividade. No caso do campo midiático, trata-se de difusão em massa de visões de mundo e leituras de acontecimentos cotidianos específicos relacionados a discursos políticos vencedores (Nogueira e Ribeiro, 2013, p. 125).

Ainda assim, o caso do presidente Chávez foi particular na história recente da América Latina, pois sua figura tomou evidência devido a sua trajetória política que esteve inegavelmente atrelada à sua presença na mídia. Os adversários e tampouco os partidários negavam o talento e a habilidade comunicativa de Chávez, além de ter sido o primeiro presidente da Venezuela a ter nascido na era da televisão (Marcano e Barrera, 2006, p. 229-230). Até mesmo a 'estreia' de Chávez no 
cenário político ocorreu de forma midiática. Em 4 de fevereiro de 1992, ele comandou uma tentativa de golpe de Estado e após o governo venezuelano debelar o movimento, forçou-se Chávez a fazer o seguinte discurso ao vivo em rede nacional:

[...] Companheiros: lamentavelmente, por enquanto, os objetivos que nos colocamos não foram atingidos na capital. Ou seja, nós, aqui em Caracas, não conseguimos controlar o poder. [...] Companheiros: ouçam esta mensagem solidária. Agradeçolhes a lealdade, valentia, o desprendimento. $\mathrm{Eu}$, ante o país e ante vocês, assumo a responsabilidade deste movimento militar bolivariano ${ }^{2}$.

O que era para ser algumas palavras pedindo a seus companheiros depor as armas, tomou proporção favorável a Chávez e negativa ao governo venezuelano do momento, comandado pelo presidente Carlos Andrés Pérez. Isso porque em 1992 a Venezuela enfrentava uma crise estrutural e sua elite não estava conseguindo encontrar um consenso mínimo para reformar o sistema político, permeado pelo descrédito eleitoral nos partidos políticos tradicionais AD e Copei ${ }^{3}$. Dessa forma, Chávez e seu discurso, sobretudo o por enquanto (por ahora), começou a representar a inúmeros eleitores venezuelanos uma alternativa política viável a fim de 'salvar a nação' ante a crise instalada. Esse clima continuou mesmo quando os militares insubordinados estavam presos em um presídio militar entre 1992 e 1994, sentenciados por terem conduzido o golpe de Estado. "O aparecimento de Chávez na televisão durou apenas um minuto. Sua consequência inesperada foi a de que passara a ser, de um oficial totalmente desconhecido, uma figura nacional" (Gott, 2004, p. 102).

$\mathrm{Na}$ época, o governo da Venezuela tentou amenizar a crescente popularidade dos militares insurretos (de Chávez em especial), eliminando a cobertura considerada elogiosa a eles nos meios de comunicação do país (Jones, 2008, p. 168-184). Contudo, isto não foi suficiente para evitar que Chávez, na esteira da popularidade obtida

\footnotetext{
${ }^{2}$ CHÁVEZ, Hugo. Pronunciamento do tenente-coronel Hugo Chávez em cadeia nacional. In. UCHOA, 2003, p. 165.

${ }^{3}$ Ação Democrática e Comitê de Organização Política e Eleitoral Independente, respectivamente. Ambos eram considerados os dois partidos políticos mais fortes naquele momento, pois eram os únicos capazes de eleger o presidente da República (Ewell, 2002, p. 327). Entre 1958 e 1998, no período conhecido na história política do país como Pacto de Punto Fijo, todos os presidentes da Venezuela pertenceram a esses dois partidos.
} 
em 1992 após aparecer em rede nacional, se elegesse presidente da República com $56 \%$ dos votos em dezembro de $1998^{4}$.

Durante sua gestão, o presidente se inseria na mídia de diferentes maneiras. As vezes combinado, outras improvisadamente. Pelo rádio, TV, Internet ou escrevendo artigos ao jornal oficialista Correo del Orinoco $^{5}$. Entretanto, era no programa dominical chamado de Alô presidente que passava boa parte desse dia anunciando políticas, demitindo ministros, cobrando de seus assessores e recebendo ligações de eleitores. De acordo com Carroll (2013), é comum um chefe de governo utilizar a mídia com a finalidade de justificar, persuadir, projetar ou polir, porém, nenhum seria como Chávez (Carroll, 2013, p. 34). Sob uma perspectiva crítica, o autor afirma que até 2010, quando Chávez já havia completado mais de dez anos no poder, havia sido realizada mais de 1900 cadeias nacionais no rádio e na televisão, o que correspondia a aproximadamente 1300 horas, ou o equivalente a 53 dias seguidos diante das câmeras (Carroll, 2013, p. 190).

A função dessas aparições midiáticas, sejam elas previamente estabelecidas ou repentinamente realizadas, não era somente ser um meio pelo qual fosse possível falar com o presidente. Era uma forma de, em suma, ele demonstrar que estava trabalhando. Krause (2013) afirma que por intermédio da mídia Chávez governava "ao vivo", criticando: "Não só governa como faz uma representação teatral de seu governo [...] No país das telenovelas, Chávez inventou um gênero alucinado, um gênero que não foi imaginado nem pelos grandes atores no poder, como Ronald Reagan" (Krauze, 2013, p. 89). Em linhas gerais, “a televisão era apenas uma dimensão, um palco eletrônico, controlado, que ocultava tanto quanto revelava" (Carroll, 2013, p. 36).

Em suma, é possível afirmar que as aparições midiáticas se confundiram com o próprio exercício do poder presidencial nos 14 anos de governo. Porém, o uso da mídia não esteve com Chávez apenas nas polêmicas a que se envolveu nesse período, a exemplo do discurso do diabo em 2006 , na áspera discussão com o Rei da Espanha em

\footnotetext{
${ }^{4}$ Fonte: $<$ http://www.cne.gob.ve/web/estadisticas/index_resultados_elecciones.php $>$ (acessado em 29 de junho de 2014).

${ }^{5}$ Nesse periódico, sua coluna semanal se chamava "artillería de ideias".

${ }^{6}$ Em discurso pronunciado na Organização das Nações Unidas, Chávez disse: "Ayer estuvo el diablo aqui, en este mismo lugar. ;Huele a azufre todavía esta mesa donde me ha tocado hablar! Ayer, señoras y señores, desde esta misma tribuna el señor presidente de los Estados Unidos, a quien llamo de el diablo, vino aqui hablando como dueño del mundo". In: CHÁVEZ, 2009, p. 469-476.
} 
20077, ou mesmo no intenso debate travado com a oposição nos 14 anos de governo. Quando foi diagnosticado com câncer em junho de 2011, as idas e vindas de Cuba para tratamento, sua convalescência, o anúncio de sua morte em 5 de março de 2013, o cortejo, o choro de seus partidários, os últimos discursos, as vitórias eleitorais, etc.; todos esses formam acontecimentos amplamente explorados pela mídia.

Todavia, para além de todo esse aparato visivelmente teatral, estava um eficiente instrumento de propaganda e de promoção das políticas do regime, ou seja, de exercício do poder. Tratava-se, segundo a lógica foucaultiana, de uma relação de poder exercida por alguém (Chávez) com incrível capacidade de inserção, mobilização e convencimento das massas em torno de suas ideias por intermédio de um discurso bem elaborado. A mídia seria apenas um dispositivo altamente eficaz para atingir tal propósito. Além disso, no começo do século XXI houve um processo de ampliação do acesso à mídia, o que não invalidou a capacidade de comunicação (uso do discurso) na construção das verdades defendidas pelo regime. Ao contrário, as incrementou, sejam elas no tocante as políticas do governo, no trato com a oposição e/ou na forma como se passou a interpretar a história durante a era Chávez. Nesse último ponto, conforme a interpretação do regime, a história da Venezuela se transformou em instrumento para legitimar Chávez como um continuador da obra de Simón Bolívar e, tal como destaca Harnecker (2002), líder de uma revolução sui generis. Em linhas gerais, visava justificar uma verdade contada a partir da visão de seus discursos.

No entanto, essa forma de exercício do poder não foi inovadora no tocante aos dispositivos utilizados para tal (mídia, instituições, ideologia, Exército, polícia, etc.), porém ela foi marcadamente particular com relação ao conteúdo utilizado para essa finalidade (o apelo ao culto à figura de Simón Bolívar com o Socialismo do Século XXI), que o levou não apenas a permanecer no poder por um longo período, como também a controlar quase a totalidade do aparelho de Estado. Portanto, exercer uma influência significativa na mídia venezuelana a fim de neutralizar o poder dos grandes meios de comunicação da Venezuela foi uma estratégia que Chávez desempenhou durante sua

\footnotetext{
${ }^{7} \mathrm{Na} 17^{\mathrm{a}}$ Cúpula Ibero-americana, realizada em Santiago (Chile), o Rei da Espanha Juan Carlos disse asperamente a Chávez "Por qué no te callas"!; após o líder venezuelano ter dito que o ex primeiro ministro espanhol, José Maria Aznar, era um fascista, pois ele havia apoiado o golpe de Estado ocorrido em abril de 2002 na Venezuela que destituiu temporariamente Chávez do poder. In: MAISONNAVE, Fabiano. Chávez e rei espanhol batem boca em cúpula. Folha de S. Paulo, São Paulo, 11 de novembro de 2007, p. A25, nº 28.711.
} 
administração. Logo no início do governo, ele chegou a afirmar que o grande problema de sua revolução era não saber se comunicar, conforme mostrou em documentário produzido por duas produtoras irlandesas, em um documentário com visão favorável ao processo político bolivariano ${ }^{8}$. Isso porque naquele momento Chávez encontrava dificuldades em divulgar as políticas do governo, devido à campanha desfavorável feita pelos grandes meios de comunicação a nível nacional.

Portanto, na Venezuela da era Chávez, a mídia acabou se tornando o dispositivo mais estratégico para um grupo se sobrepor a outro. De acordo com Valente (2007), "os dois lados que disputavam o poder em Caracas travaram uma verdadeira guerra de comunicação, com o objetivo de ganhar a adesão dos venezuelanos [...]" (Valente, 2007, p. 130). Isso ficou evidenciado em abril de 2002 quando setores das Forças Armadas, empresários e os donos das grandes emissoras de TV do país orquestraram (como o 'secreto' apoio dos Estados Unidos) um golpe de Estado contra Chávez. Ele foi detido e enviado à Ilha de La Orilla, ficando ausente da presidência por 48 horas. Nesse ínterim, os golpistas deram posse a um governo provisório, comandado pelo empresário Pedro Carmona. A mídia contrária a Chávez realizou um serviço de informação e contrainformação, fechando a emissora de TV estatal, rádios comunitárias e jornais favoráveis a Chávez (Rovai, 2007, p. 49-52). Embora tal estratégia não tenha sido exitosa, pois ele retornou ao poder horas mais tarde, esse episódio tornou-se conhecido como golpe midiático-militar, devido ao papel central desempenhado pela mídia privada e por seus proprietários na derrubada temporária do presidente.

Como resultado, o governo da Venezuela começou a investir maciçamente na mídia estatal. Em 2005, já contava com ampla rede de comunicação, que incluía quatro canais de TV, por volta de oito jornais e revistas, e duas agências eletrônicas de noticiais. Todas essas mídias contavam com a presença absoluta do presidente Chávez, conforme noticiou o jornal brasileiro Folha de S. Paulo, periódico que publicava matérias críticas ao regime 9 . Contudo, o empreendimento mais ambicioso foi a Televisión del Sur (Telesur). Fundada em 2005, esse canal de TV multiestatal visava ser um meio para promover a integração dos povos latino-americanos, a exemplo do que Simón Bolívar havia

\footnotetext{
${ }^{8}$ BARTLEY e O’BRIAN. “The Revolution will not be televised”. Documentário (2002).

${ }^{9}$ ANTUNES, Cláudia. "Governo conta com vasta rede de comunicação pública”. Folha de $S$. Paulo, São Paulo, 28 de junho de 2005, p. 12.
} 
preconizado no século XIX. "A Telesur sempre fez parte do projeto midiático esboçado por Chávez - que tinha como um de seus pilares de governo a comunicação - e [...] representava o espaço pelo qual ele podia propagar as suas ideias bolivarianas para o mundo" (Nogueira e Ribeiro, 2013, p. 126). A Telesur cobriu amplamente o funeral de Chávez, o cortejo e o anúncio de sua morte, eventos transmitidos ao vivo sob um clima de luto, além de que entre 2011 e 2013 a emissora colaborou com o regime ao fornecer poucas e vagas informações sobre o real estado de saúde do presidente e do local onde se encontrava alojado o câncer.

Por outro lado, o governo da Venezuela instituiu dispositivos jurídicos visando punir as emissoras de TVs privadas oposicionistas. Em 2007, a concessão de uma das principais emissoras de TV do país, a RCTV (Radio Caracas de Televisão), foi cancelada pelo governo (Krauze, 2013, p. 88). Ela também havia participado do golpe contra Chávez em abril de 2002, motivo pelo qual a retirada da concessão foi justificada. Na verdade, a relação de Chávez com a mídia privada sempre foi controversa e complexa, sendo que ambos os lados criaram e sustentaram um clima de recíproca perseguição (Nogueira e Ribeiro, 2013, p. 126).

Contudo, o bom uso da mídia como uma forma de propagar o discurso e, consequentemente, de estabelecer uma relação de poder, não foi uma inovação trazida por Chávez ao cenário político nacional e internacional. $\mathrm{O}$ fato de ter sido um presidente midiático não explica a totalidade de seu êxito como um líder que se submeteu a 13 eleições e foi derrotado em apenas uma. Porém, o fato de ser midiático foi capaz de lhe outorgar a imagem de alguém eleitoralmente imbatível, devido a sua presença cada vez mais intensa na mídia. Além disso, seus partidários pareciam gostar de vê-lo na mídia e de interagir com ele através dela, se sentindo como um agente ativo nas decisões políticas. $\mathrm{Na}$ verdade, se tratava de uma sensação mais aparente do que real, pois a mídia exerceu um papel no governo Chávez de um dispositivo capaz de proporcionar evidência (rápida, pomposa e superlativa) a suas políticas. Tratava-se naturalmente de uma relação de poder em que um líder se sentia o 'legítimo' representante de um povo, exercendo poder sobre ele, enquanto esse 'povo' exercia um poder sobre Chávez, tendo em vista que sua permanência no cargo dependia de que continuasse existindo essa aceitação.

Dessa forma, a importância exercida pelo dispositivo mídia e o fato de Chávez ter sido um presidente midiático são inegáveis, assim como o 
exercício do poder presidencial através dela, a aceitação de sua liderança por parte da sociedade e a resistência a suas políticas junto àqueles setores sociais contrários à Chávez, com o qual ele travou uma 'guerra política/midiática' nos 14 anos em que permaneceu na presidência da República, desde sua posse em fevereiro de 1999 até sua morte em março de 2013.

\section{Considerações Finais}

Há a possibilidade de se analisar a Venezuela da era Chávez de muitas formas e com inúmeros referenciais teórico-metodológicos. Contudo, para fins desse artigo, os discursos e o uso da mídia como uma forma de exercício de poder e principal ponto na relação de poder existente entre Chávez e seus governados, foi o ponto de partida escolhido para desenvolver a respectiva análise. Também como uma opção dos autores, os conceitos utilizados como referenciais nesse trabalho (discurso, poder e mídia/dispositivo) foram analisados com base no entendimento que Michel Foucault possuía em relação a eles no vasto cabedal epistemológico desse pensador.

O poder como uma relação bilateral e existente em todo tipo de relação humana, sendo socialmente pulverizada; os discursos como produtores de verdades; e a mídia como um dispositivo utilizado, seja por uma instituição ou pessoa, como um instrumento para exercer o domínio, ou manter posições em determinada estrutura social. A constante presença de Chávez na mídia - o que lhe outorgou o adjetivo de presidente midiático - e o impacto (seja ele positivo ou negativo) que seus discursos possuíam ao influenciar o cenário político da Venezuela entre 1999 e 2013, são capazes de evidenciar a plausibilidade dos conceitos acima utilizados para fundamentar este trabalho.

A Venezuela no período de 1999 a 2013 foi uma realidade interessante de se analisar, principalmente sob o aspecto de como o discurso de um líder, portador de uma inflamada oratória e um marcante carisma, empolgou os partidários e 'chocou' os adversários. Chávez foi capaz de se manter na presidência da República por 14 anos em um cenário político com eleições relativamente competitivas, fazendo com que seus adversários se desdobrassem de várias formas e estratégias para vencêlo eleitoralmente. Ademais, conseguiu resistir às tentativas da oposição de retirá-lo do poder por intermédio de táticas nãoinstitucionais, tal como ocorreu na tentativa de golpe de Estado em abril de 2002 ou na 
greve petroleira de 2003, evento esse que parou o setor produtivo do país durante vários meses.

Chávez predominou no cenário político do país a ponto de se colocar acima dos partidos políticos. Nos quatorze anos como presidente da República, venceu 13 das 14 eleições, referendos, plebiscitos e demais consultas populares, dentre as quais a Constituição em 1999, referendada em plebiscito, algo considerado inédito na história política do país, mas que somente poderia ter sido produzido mediante tais condições históricas. Dentre as verdades defendidas pelo regime estava o fato do presidente Chávez se colocar como o continuador da obra iniciada por Simón Bolívar no século XIX. Segundo a interpretação 'oficial', Chávez era o 'segundo libertador', pois ocupava a presidência da República com o propósito de libertar o povo venezuelano da dominação oligárquica e dos países centrais (em especial, dos Estados Unidos). Tal lógica não apenas fazia parte dos discursos de Chávez, ela era o seu discurso.

Por isso a mídia se tornou o dispositivo mais essencial nessa disputa, tendo em vista que a era Chávez foi um período de grande efervescência política, onde o uso da mídia foi primordial na construção de verdades, as quais foram diferentes de acordo com os lados em disputa. Por exemplo, a imprensa privada venezuelana, em sua maioria contra o governo Chávez, reforçava as características autoritárias do regime e a supremacia do poder Executivo, compreendendo tais pontos como uma completa ausência de democracia. Por outro lado, o governo enfatizava as conquistas sociais obtidas a partir da subida nos preços do petróleo no mercado internacional e da vontade do presidente Chávez em distribuí-las com a população. Muitas vezes, os resultados não eram tão amplos, porém, a forma como Chávez os divulgava e explicava para o público, as fazia tomar uma proporção maior do que muitas vezes possuía. Com o maciço investimento do governo da Venezuela na imprensa oficial a partir de 2003, Chávez obteve mais espaço nos meios de comunicações e o resultado foi que durante seu governo o país viveu um clima de tensão e uma 'guerra de versões', as quais foram destoantes no entendimento dos acontecimentos políticos.

O bom exercício do discurso como uma forma de exercer o poder, em alguns casos até mesmo se confundindo com ele, não foi inventado ou iniciado com Chávez. Entretanto, o momento histórico em que exerceu a presidência da República foi marcado pela intensa diversificação de mídias, acompanhado pela ampliação em seu acesso, simbolizado na popularização da Internet e na melhora da qualidade das imagens através das TVs digitais. 


\section{Referência}

ANTUNES, Cláudia. Governo conta com vasta rede de comunicação pública. Folha de São Paulo, 28 de junho de 2005, p. 12, n 27.845.

BARTLEY, Kim; O'BRIAN, Donnacha. "The Revolution will not be televised". Documentário (2002). Disponível em: <https://www.youtube.com/ watch? $\mathrm{v}=3$ ZajyVas4Jg>. Acesso em: 19 jun. 2014.

CARROLL, Rory. Comandante: a Venezuela de Hugo Chávez. Tradução de George Schlesinger. Rio de Janeiro: Intrínseca, 2013.

CHARTIER, Roger. A história cultural: entre práticas e representações. Lisboa: Difel, 1990.

CHÁVEZ, Hugo. Pronunciamento do tenente-coronel Hugo Chávez em cadeia nacional. In: UCHOA, Pablo. Venezuela: a encruzilhada de Hugo Chávez. São Paulo: Globo, 2003.

CHÁVEZ, Hugo. Discurso del presidente de la República Bolivariana de Venezuela, Hugo Chávez Frías, con motivo de la LXI Asamblea General de la Organización de las Naciones Unidas. Sede de las Naciones Unidas, Nueva York, Estado Unidos, 20 de septiembre de 2006. In: 2006 “Año de la participación y el poder popular”. Selección de discursos del presidente de la República Bolivariana de Venezuela Hugo Chávez Frías. Ediciones de la presidencia de la República, Caracas-Venezuela, 2009.

DREYFUS, Hubert. Michel Foucault: uma trajetória filosófica - para além do estruturalismo e da hermenêutica. Tradução de Vera Porto Carrero. Rio de Janeiro: Forense Universitária, 1995.

EWELL, Judith. Venezuela, 1930-1990. In: BETHELL, Lelie (Org.). Historia de América Latina: los países andinos desde 1930. Traducción de Jordi Beltrán. Barcelona: Editorial Crítica, 2002, p. 301-356.

FOUCAULT, Michel. A arqueologia do saber. 8. ed. Tradução de Luiz Felipe Baeta Neves. Rio de Janeiro: Forense Universitária, 2013.

FOUCAULT, Michel. A ordem do discurso. 22. ed. Tradução de Laura Fraga de Almeida Sampaio. São Paulo: Edições Loyola, 2012.

FOUCAULT, Michel. As palavras e as coisas. 9. ed. Tradução de Salma Tannus Muchail. São Paulo: Martins Fontes, 2007.

FOUCAULT, Michel. Microfisica do poder. 26. ed. São Paulo: Graal, 2013b.

FOUCAULT, Michel. Sujeito e poder. In: DREYFUS, Hubert. Michel Foucault: uma trajetória filosófica - para além do estruturalismo e da hermenêutica. Tradução de Vera Porto Carrero. Rio de Janeiro: Forense Universitária, 1995. p. 231-249.

GOTT, Richard. À sombra do libertador: Hugo Chávez Frías e a transformação da Venezuela. Tradução de Ana Corbisier. São Paulo: Expressão Popular, 2004.

HARNEKER, Marta. Venezuela: una revolución sui géneris. In: Ponencia para el seminario de LAC (Foro Social Mundial III). Enero de 2002. p. 15.

JONES, Bart. Hugo Chávez: da origem simples ao ideário da revolução permanente. Tradução de Rodrigo Castro. São Paulo: Novo Contexto, 2008.

KRAUSE, Enrique. O poder e o delírio. Tradução de Luis Reyes Gil. São Paulo: Benvirá, 2013. 
MAISONNAVE, Fabiano. Chávez e rei espanhol batem boca em cúpula. Folha de $S$. Paulo, São Paulo, 11 de novembro de 2007, p. A25, № 28.711.

MARCANO, Cristina; BARRERA, Alberto. Hugo Chávez sem uniforme: uma história pessoal. Tradução de Marcos Santarrita. Rio de Janeiro: Gryphus, 2006.

NOGUEIRA, Silvia Garcia; RIBEIRO, Alana Maria. A Telesur e a construção simbólica da integração latino-americana durante e depois da era Chávez. In: Revista Sulamericana de Ciência Política, v. 1, n. 3, p. 123-131, 2013.

ROVAI, Renato. Midiático poder: o caso Venezuela e a guerrilha informativa. São Paulo: Publisher Brasil, 2007.

VALENTE, Leonardo. Politica externa na era da informação: o novo jogo do poder, as novas diplomacias e a mídia como instrumento de Estado nas Relações Internacionais. Rio de Janeiro: Revan, 2007.

VEYNE, Paul. Foucault: seu pensamento, sua pessoa. Tradução de Marcelo Marques de Morais. Rio de Janeiro: Civilização Brasileira, 2011.

WEBER, Max. Os três tipos puros de dominação legítima. In: Coleção Grandes Cientistas sociais. 3· ed. São Paulo: Ática, 1986. 